\title{
INFORMATION SYSTEM DESIGN OF PERFORMANCE ACHIEVEMENTS MONITORING IN THE UNIVERSITY: A CASE STUDY IN BINUS UNIVERSITY
}

\author{
Irma Irawati Ibrahim; Cuk Tho \\ School of Computer Science, Bina Nusantara University \\ J1 KH Syahdan 9, Jakarta 11480, Indonesia. \\ irma.irawati@binus.edu,Cuktho@binus.edu
}

\begin{abstract}
Dashboard is a computer interface that displays a variety of charts, graphs, tables, which are selected reports from various data that are considered important to display rapidly, with an attractive appearance, dynamic, and relevant so that it can immediately be seen quickly to analyze a condition. Dashboard information system is widely used in various companies as a support system for decision-making where Dashboard usually displays data business trends of the company or the achievement of KPI (Key Performance Indicator) of a company. The method used is descriptive analysis by means of collecting information that areimportant for universities to be considered asthe Key Success Factors (KSF) of the university, and then, the design of the dashboard is made in accordance with these important factors. The result of this study is a grand design of information systems for the university performance monitoring, starting from the reception of students, faculty performance, student academic achievement, effectiveness and efficiency of services, including graduates. It is expected that by the time the system has been fully implemented, the university can take action quickly and accurately with respect to the required conditions.
\end{abstract}

Keywords: Information System Dashboard; Dashboard; Academic Dashboard; University Dashboard

\section{INTRODUCTION}

Quality is one of the crucial aspects in an organization that is engaged either in profit or nonprofit. The same thing happens in education, where the quality is one of the important aspects which make an educational institution is selected chosen. Bina Nusantara University is selected to be the research object since the educational quality is the main factor of concern from the educational implementation in the university. Bina Nusantara University has numerous study programs, which generates various graduates in D3, S1, S2, and S3, which has collaboration with overseas university in the implementation. The collaboration is carried out both in the field of learning and research.

To ensure the learning quality, the monitoring towards the performance of both the academic and non-academic becomes important. Therefore, the monitoring system is designed by using information technology. The system will help the leader in monitoring operational activity in a form of implementation of daily learning process. The result of the learning process will be known through the academic results of every student. Not only the student's academic results, but also the performance system of every lecturers and employees will be able to be monitored. The monitoring results will be used to do necessary corrective actions or other actions In order to be able to accelerate can achievement of predetermined targets.

By fully utilizing the technology in business world nowadays, the businessmen and managers always need the comprehension data or business reports, which are obtained from various sources like Enterprise Resource Planning (ERP), performance scorecards, and business intelligence (BI) [1]. If the plenty of information is not presented in the right and suitable display, it will cause information overload and it will also make the information becomes useless or even mislead. The solution of the information overload is offered by dashboard concept providing package information display view which is the combination of various sources, such as management performance, strategy map, scorecards, and business intelligent as One Manageable Solution. Although at this time there is no dashboard that can be categorized as standard reference, but according to ref [1], a dashboard is expected to be able to collect, conclude, and provide information from several sources like ERP and Business Intelligent, so in one look the user can get the conclusion about the company recent situation. 
In America and England, 40\% of companies that engages in the services have utilized dashboard technology as substantial data reports that are Key Success Factor of the companies [2]. A lot of service companies use dashboard to track marketing effectiveness and guide business decisions and also business communication. The service companies are pay-TV broadcasting (British Sky), consumer credit (e.g., Capital One), online services (e.g., Google), gaming (e.g., Harrah's), hospitality (e.g., Hilton), investment banking (e.g., Morgan Stanley), systems integration (e.g., Unisys), and mutual funds (e.g., Vanguard).

Education as one of the service institutions, by seeing previous situation it does not dismiss the possibility of the needs of dashboard to monitor its performance and also to become resources to take strategic decision. Surely university needs fast resources to take strategic decisions, in Indonesia it unclearly applies fast and recorded information concept as dashboard concept, this possibly obstructs the university development to be more effective and efficient in doing activities. By doing this research the writer wants to provide an information system design that can help university in monitoring its performances, by serving fast and relevant information, and also with quick information portraits like graphs and charts view.

The aims of this research are: (1) To identify dan collect information regarding to Key Success Factor (KSF) in college. (2) To analyze and design information system that is needed by college in monitoring relate to Key Success Factor (KSF) in college.

The benefits of this research are: (1) To have information regarding to Key Success Factor (KSF) in college. (2) To have information system design that needed by college in mentoring Key Success Factor (KSF) in university.

According to ref [2], dashboard based on its usage and purpose has four characteristics, which are (1) A dashboard can be made as a tool that can force cross unit or department to have size and consistent performance measurements. (2) Dashboard helps performance monitoring, to know who or what that has good or bad performances and to learn the previous performances situation to develop the next performances. (3) Dashboard can be used as communication tools to the important stakeholder.

There are five steps in the dashboard development, which are (1) the choice of Key Matric with two approaches; general and tailored. General approach is done with surveying to all connected departments, meanwhile tailored approach is done with involving high level communication to know important things and highly beneficial for a business company; (2) Data population for dashboard; (3) To build relation among dashboard item. (4) Forecasting and Scenarios. (5) To connect information in dashboard with finance consequences.

Dashboard is used to increase the productivity and business values in marketing with describing and monitoring business operational. The sophisticated dashboard devices depict various important components, for instance KPI, business model, monitoring business, Business Performance Management (BPM), etc. An integrated data enables dashboard development cost and time which is not a little, but ref [3] introduces dashboard development with Model-Driven approach that is claimed that it can be easily and fast developed, with flexible design and good performances. With Model-Driven framework, when the user has decided functions that are provided in this model, this framework will automatically generate code to dashboard creation, and it only needs minor adjustment done by the developer. This creation has involved all needed aspects by dashboard which is data management, data display in various options, data relation, and user management. The used approach is focus suppression from the developer where developer is only emphasized to focus towards desired functions, meanwhile for data display and design become framework dashboard job. In other words developer is not confused to design interface and data component, only focus in desired functions.

A university dashboard is developed in Romanian University [4]. The dashboard development needs to be done because the university faces problems in getting fast and accurate information relating to its position in educational industry. The information is needed by the university to make short-term decision, long-term plan, provision of relevant education for students' needs continuously, serving the needed report, and keep serving interesting educational program for college students to maintain their interest in learning in the university or attract prospective students. The built dashboard is tailored to dashboard characteristic, which uses visual components (charts, performance bars, gauges, maps, stoplights, etc) to highlight data and exceptions that needs further action; collect data from various information system sources, enable to do drill-down to underlying data sources; show dynamic real time data, single view business data and can refresh data anytime; not only present financial matric data to be more effective; display key performance indicators in brief and intuitive format; help monitoring individually, business unit, and organizational performance and processes for the board organization needs; not always in portal form; and easy to use. The presented dashboard data covers all data levels that classified in fundamental groups which are Student, Teaching \& Learning dashboards, Faculty dashboard, Finance dashboards, Research dashboard, Staff \&workplace satisfaction dashboards, University Business Processes \& 
Operations dashboards.

A report from the Center on Educational Governance/University of Southern California is depicted that USC School Performance Dashboard 2011 data structure consists of three levels, which are (1) Data from annual mandatory report. (2) Academic data; (3) Key indicator - Financial Resource and Investment, School Quality, School Performance, and Academic Productivity.

\section{METHOD}

The research approach method that will be used is descriptive analytical. Descriptive research means gathering information about certain examined situation, so the problems and the solutions can be recognized. The taken descriptive research is a descriptive case study in Binus University. Meanwhile the data collection is done by observation and interviews, and also literature studies. This research will explain the making process of academic dashboard which is expected can give solutions to some problems that occurred in management level relating to data collection to do business analysis or academic performance in Binus University.

The outline framework in this research covers: (1) Define - Determination of the project scope. Document surveys are needed to know the main focus that is wanted to be presented in dashboard in this process. This process also determines the project timeline. If the project is thought too big, the manufacture project for this dashboard will be implemented in many levels. Besides the interviews there will be related document collections. (2) Requirement Collection and Analysis - The general needs of the system will be known from the first process. Then it will be done more detailed needed assessment and needed analysis to enter the development level. In this process the benchmark literature studies is used to create university dashboard design. (3) Design - the making design is based on needed analysis.

\section{RESULTS AND DISCUSSION}

\section{Define}

The dashboard making studies will be done in BINUS University. The thing that is going to be done in making the university dashboard design is by determining Key Success Factor in BINUS University. Some things or documents can be used as references in determining KSF in BINUS University, such as university quality objectives, University accreditation report to educational ministry, and also Key Performance Indicator.

\section{Requirement Capture}

To find out the system requirement, this study is done towards BINUS University quality objectives,
University accreditation report to educational ministry, and also Key Performance Indicator. BINUS University has 6 quality objectives, namely: (1) One of three graduates becomes entrepreneur or works in global organization within six months since the graduation day. (2) 25 innovations per year and patented. (3) The average of the lecturers has one international paper per year. (4) $20 \%$ of active students have international experiences during learning process. (5) 75\% satisfaction of academic satisfaction index, taken from students' questioner results towards lecturers and also the lecturers' Key Performance Indicator results. (6) Stakeholder satisfaction is taken from students, lecturers, and parents survey results.

Some main factors from university accreditation report to the government consist of: admission student data (target, registration, take the exam, pass the exam, new student's profile transfer/ non transfer); the average graduate study period (in year); the average of graduates' IPK in the last five years; the percentage of foreign students towards the total of students; awards for student achievement in academics; the percentage of on-time graduation; and the percentage of drop out or resign students; the ratio of the numbers of the lecturers with students; the lecturers' education; the average of lecturer work load per semester in credit semester; the percentage of non-fixed lecturers toward the total lecturers; the maximum total of advisory students that are advised by an advisory lecturer as chief adviser (the main adviser) and members; the length average of thesis in the last three years; the total of research (journal/ proceeding/article) per lecturer (local, national, international); Student Creativity Program activity that is done by lecturers.

If it is seen in several KPI in BINUS University, it can be concluded that some of these factors are important factors in BINUS University, which are the numbers of new students; students retention rate; teaching quality and services (students to lecturers survey and also lecturers' KPI); the students' quality (students' KPI, on-time graduation), internationalization, and lecturers' JJA. From the analysis document results it can be concluded that KSF BINUS University can be grouped into 6 groups, namely intake (new students), students, lecturers, internationalization, graduate, and innovation.

\section{Design}

To clarify the dashboard design of this university, it can be seen on use case, ERD and Graphic User Interface in Fig. 1-8 


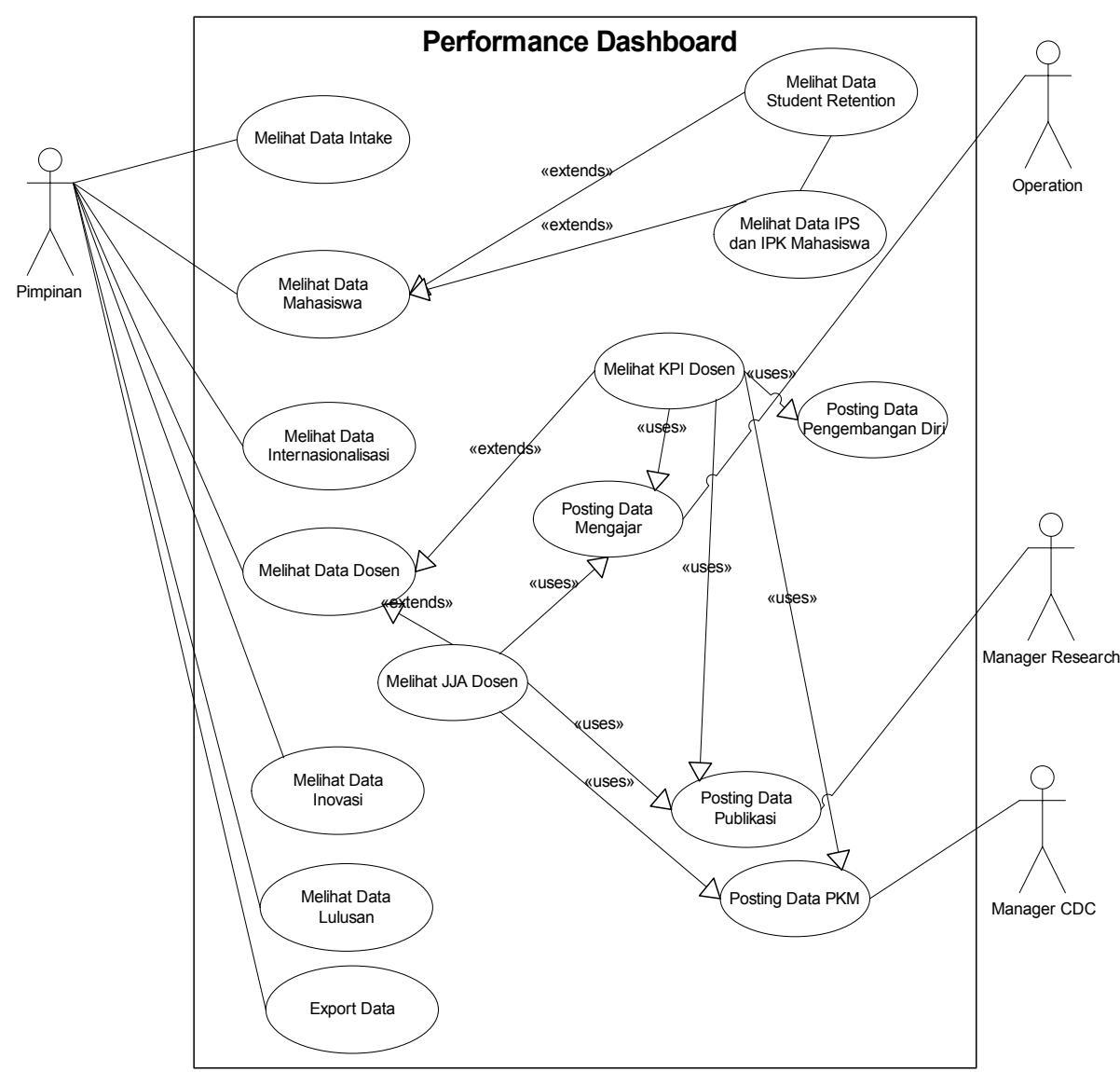

Fig 1: Use Case

Actor or user who gets involved in dashboard is divided into Leader, operation, Manager LRC, Manager Research, Manager CDC and Manager Knowledge Management. This dashboard is designed for the leader to monitor and evaluate performance from every indicator that has been set and also to monitor the running operations. The provided available access for leader is only view, with accessible data as follows: (1) Intake data: it contains new student reception including registrant data, registrant school, test participant, the test-passed passed participant and re-registration participant. This data will be managed by marketing department.(2) Student data: it contains the progress student result data shown per class, per course, per program or per faculty. Besides that data of active, leave, resign, and drop out students can be accessed through this menu. This data will be managed by involved manager in daily operational in university has responsible on the student data. (3) Internationalization data: it covers internalization activity data including seminar by abroad speaker, exchange student, and internship program in overseas company, or overseas visiting done by student. It will be managed by international office. (4) Lecturer data: it covers lecturer's teaching data, lecturer performance data in KPI form, also lecturer's educational position. To get the JJA data, it needs data from teaching, observation/publication and dedication to community. KPI and JJA data will be managed by operational manager that in charge on lecturer's data. While publication data will be managed by research office department and community dedication by community development center. (5) Innovation data: innovation data is the amount of innovation that well done, it is shown on dashboard, while innovation details will be included into provided portal knowledge management. (6) Graduate data: the graduate data present the numbers of graduate, graduation period and its graduate IPK. It will be managed by operation manager. 


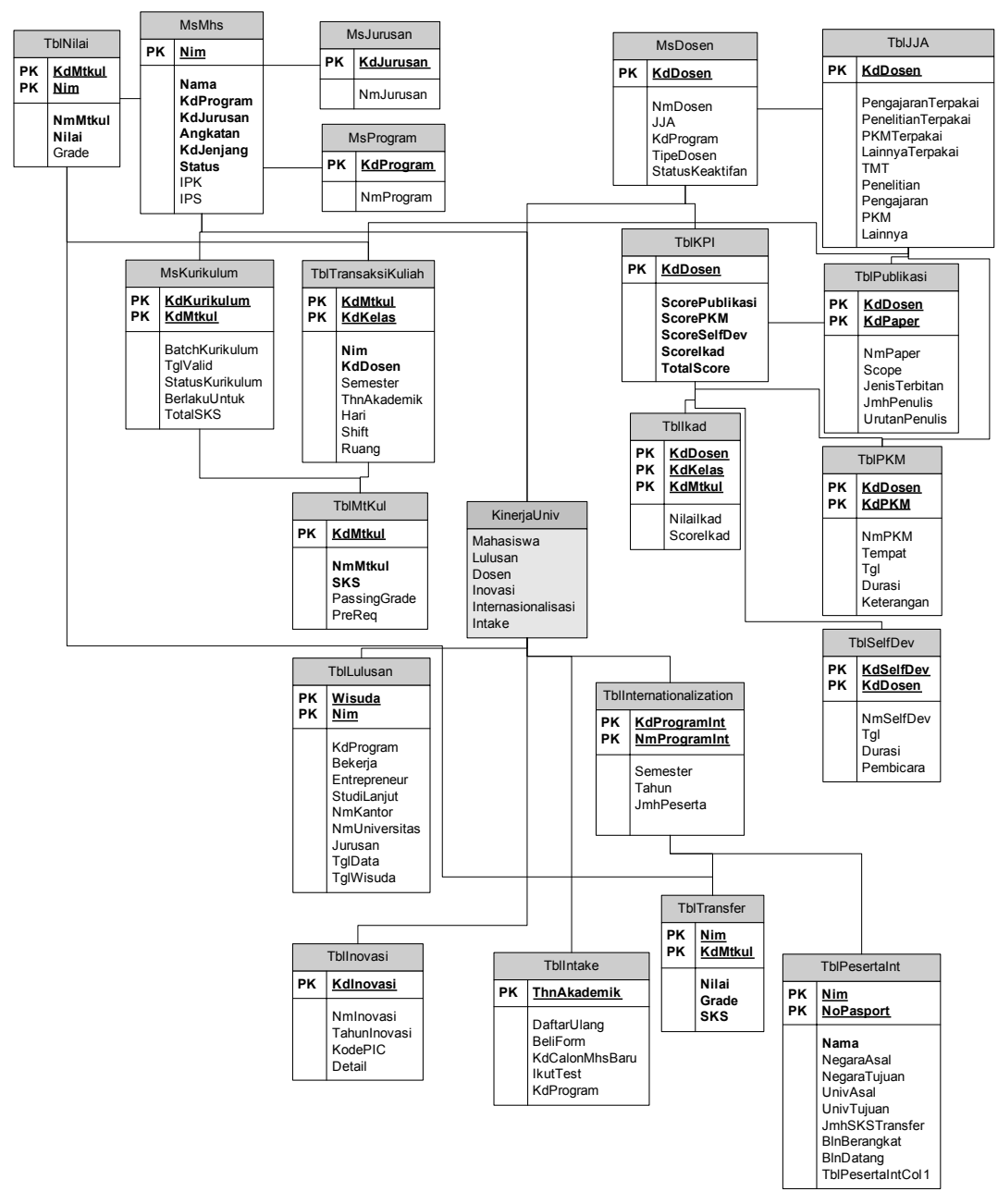

Fig 2: ERD

For the used database design can be seen on Fig. 2 ERD which is shown in the previous page. The used tables are:

Student

MsMhs

MsJurusan

MSProgram

MsKurikulum

TblNilai

TblTransaksiKuliah

\section{Lecturer}

MsDosen

TblJJATblKPI

Tblikad

TblPublikasi

TblPKM

TblSelfDev

Graduate

TblLulusan

Internationalization
TblInternationalization

TblTransfer

TblPesertaInt

Intake

TblIntake

Innovation

TblInovasi

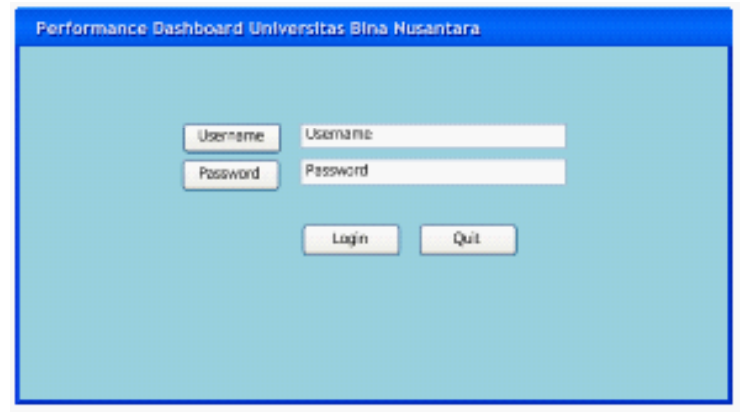

Fig 3: Login Screen 


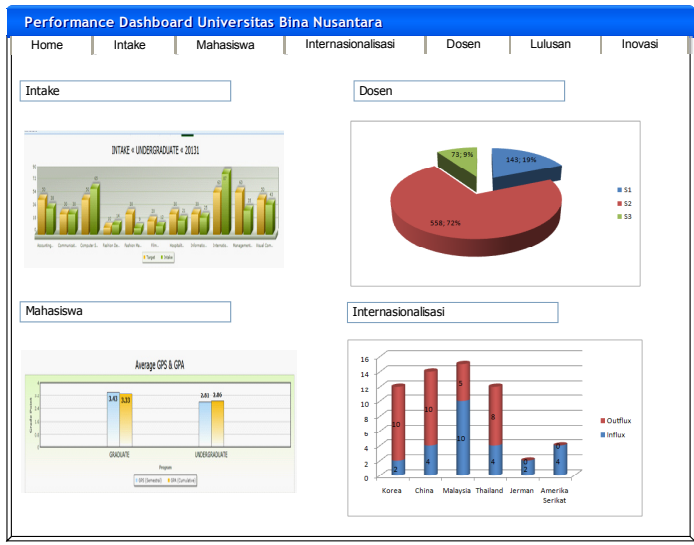

Fig 4: Menu Home Screen

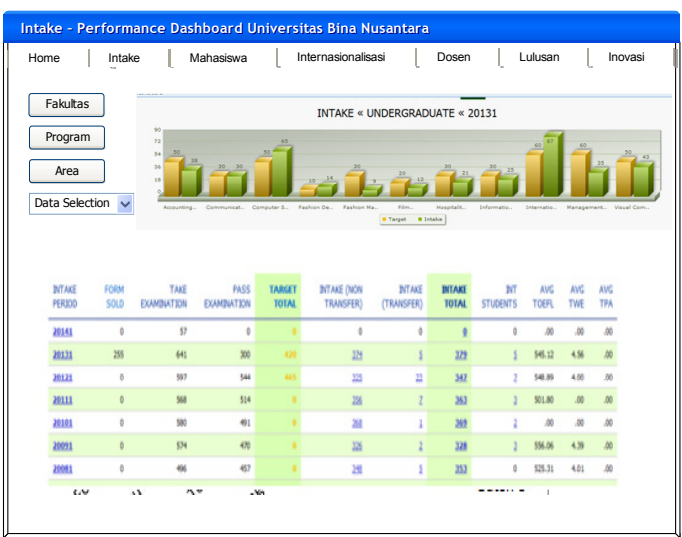

Fig 5: Menu Intake Screen

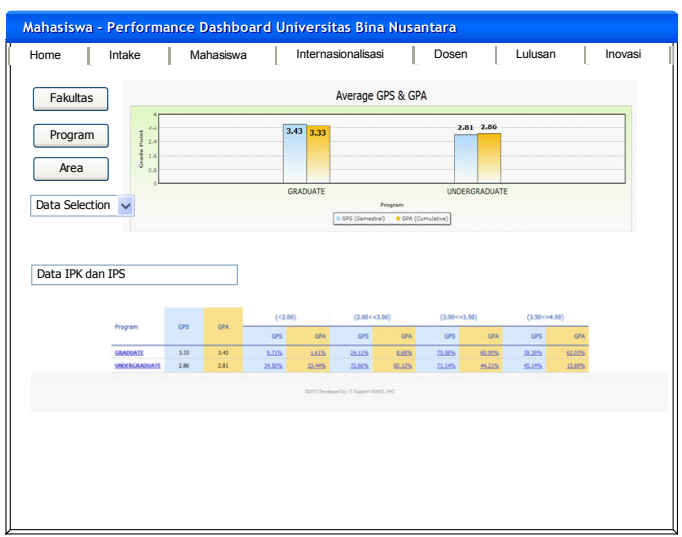

Fig 6: Student Menu Screen

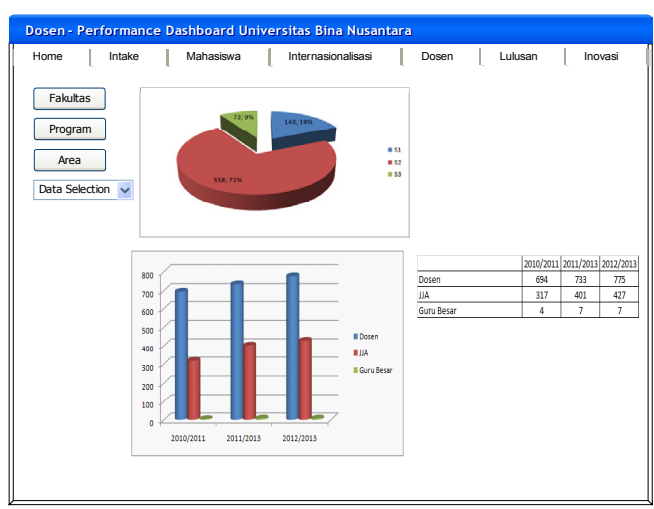

Fig 7: Lecturer Menu Screen

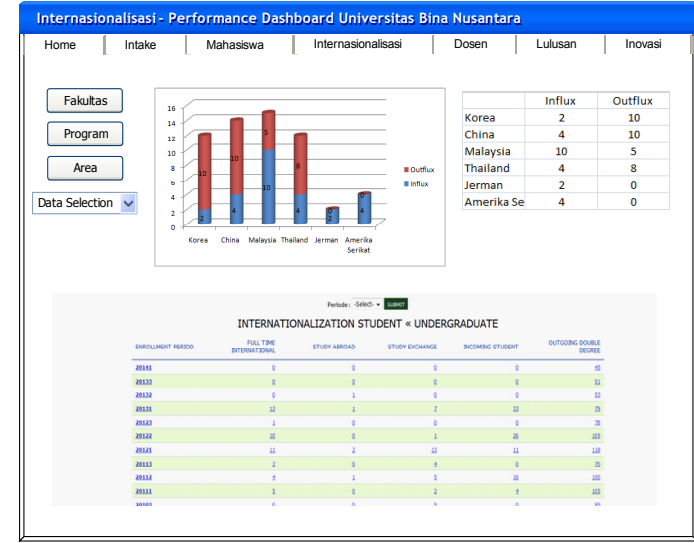

Fig 8: Internationalization Menu Screen

On the beginning screen, user is asked to login with username and password which gives access right to other menu has been matched with each user level (Figure 3). After the user login, then the user will enter the Home menu. On home, it will be shown the summary from performance achievement in graphic. By viewing the summary, the leader can observe which indicator that has good achievement and which one needs further concern.

Tabs menu will appear on every screen, where the tabs consist of intake, student, internationalization, lecturer, graduate, and innovation. In intake menu (Figure 5) it will be shown the numbers of participant, the test participant, the passed participant, and the re-registration participant. Moreover the data can be seen per faculty, program, and area. The user can also change the shown graphic when accessing the menu. To view data details, the user can click on the shown numbers.

The next screen design is student menu (Fig 6 ), where on this menu the learning performance from active student is shown, furthermore it can be seen the numbers of active, leave, and resign student for per faculty, program, and per area. Next is lecturer menu (Fig 7), it can be seen the lecturer demographic in educational level, age, and position academic level. Lecturer performance consists of teaching, research and community dedication can be seen in this menu.

Next is internationalization menu, besides the numbers of international participant that can be viewed per faculty, program and area, but also presented the name of participant's origin country and destination learning country from BINUS University student. For detail data, can click the number, and the display can be modified by the user, so the user can choose the priority menu. As for the shown menu above are menu for leader's access. 


\section{CONCLUSION}

To collect the university dashboard system needs, it can be done with survey or research towards some university documents, such as KPI, University to government report, the mission vision of the University, and etc. Starting from the document analysis and grouping needs, system design, which needed by the university, can be obtained. Given the need for academic monitoring is the same in almost every university, the University dashboard design from this research is expected to be useful for university input in revising the academic monitoring. Furthermore the university dashboard design studies can be developed further with complete facility suitable with each institution.

\section{REFERENCES}

[1] Yigitbasioglu, O.M., Velcu, O.Areview of dashboards in performance management: Implications for design and research. International Journal of Accounting Information Systems. 13, 41-59,2012

[2] Pauwels, K. et.al. Dashboards as a Service Why, What, How, and What Research Is Needed? Journal of Service Research.12 (2), 175-189,2009

[3] Palpanas, T. et.al. Integrated Model-Driven Dashboard Development. Springer Science + Business Media, LLC. 2007

[4] Muntean, M. et.al. Performance Dashboards for Universities. Proceedings of the 2nd International Conference on Manufacturing Engineering, Quality and Production Systems, 206-211,2010 